\title{
A EXCEÇÃO DE ORDEM PÚBLICA INTERNACIONAL
}

THE INTERNATIONAL PUBLIC POLICY EXCEPTION

\section{Gustavo Ferraz de Campos Monaco*}

\begin{abstract}
Resumo:
A ordem pública coloca em evidência os valores fundamentais de um foro e manifesta-se por três diferentes modos no âmbito do Direito Internacional Privado, a saber: pela estatuição de normas de aplicação imediata, pela construção de normas de conflito com conexões alternativas e axiologicamente orientadas a partir dos valores do foro e pela incidência do princípio da ordem pública.
\end{abstract}

Palavras-chave: Conflito de leis no espaço. Normas de aplicação imediata. Conexões alternativas. Princípio da ordem pública.

\begin{abstract}
:
Public policy highlights the fundamental values of a forum and is manifested in three different ways in the field of Private International Law, namely: the establishment of lois de police, the construction of conflict rules with alternative and axiologically oriented connections on the basis of the values of the forum and the effect of the principle of public policy.
\end{abstract}

Keywords: Conflict of laws. Lois de police. Alternative connections. Principle of public policy.

\section{Introdução $^{1}$}

Escolhi para esta prova de erudição o ponto n. 11 do Edital, que é, também, um dos pontos do Programa da Disciplina DIN0314, que versa sobre a Teoria Geral do Direito Internacional Privado e se aprofunda no estudo dos conflitos de leis no espaço. Este é, como se sabe, um dos objetos de preocupação dessa multissecular disciplina. "A exceção de ordem pública internacional" é o título desse ponto que, a meu ver, merece ser mais bem explicitado para que possamos compreender seu objetivo específico, sendo esse, portanto, meu ponto de partida.

Procurarei refletir sobre o significado dessa expressão - "a exceção de ordem pública internacional" - a partir de duas passagens retiradas da literatura estrangeira do

\footnotetext{
* Professor Titular de Direito Internacional Privado da Faculdade de Direito da Universidade de São Paulo, lotado no Departamento de Direito Internacional e Comparado; Livre-Docente, Doutor e Bacharel pela mesma Faculdade; Mestre em Ciências Jurídico-Políticas pela Faculdade de Direito da Universidade de Coimbra; Autor de diversos livros e artigos na área. Endereço eletrônico: gfcmonaco@usp.br.

1 Mantive, nessa publicação, o tom expositivo com o qual elaborei o texto que serviu de base à prova de erudição realizada no âmbito do concurso que me indicou, por unanimidade, para prover o cargo de Titular de Direito Internacional Privado na Faculdade de Direito da USP.
} 
Direito Internacional Privado, distantes como estão uma da outra no tempo, separadas por mais de 65 anos desde que Hans Lewald e Hélène Gaudemet-Tallon ministraram seus Cursos na Academia de Direito Internacional da Haia, cursos esses que foram publicados, respectivamente, em 1939 e 2005.

$\mathrm{O}$ autor alemão, em seu Mise en oeuvre de la règle de conflit, coloca-se diante de duas questões a respeito do raciocínio a ser feito pelo juiz diante da ordem pública de seu país. E ele afirma serem duas as possibilidades que se apresentam ao espírito do magistrado. Na primeira, esse agente público concluiria que em virtude da regra de conflito deveria ser aplicada a lei do Estado A. No entanto, o resultado que esta lei pode produzir mostra-se intolerável na medida em que incompatível com os princípios fundamentais da legislação do foro. Percebe-se, aqui, que os valores fundamentais do foro são o ponto de chegada do raciocínio e que eles só emergem em razão do risco de que se produza um intolerável. Por isso, é necessário impedir que esses efeitos se concretizem. Na segunda, ao contrário, o agente público toma tais valores como ponto de partida imediato. É que a lei do foro conteria certos valores fundamentais cuja aplicação seria absolutamente necessário garantir, ainda que a regra de conflitos determinasse a aplicação de uma lei estrangeira. (LEWALD, 1939, p. 118-119).

Gostaria de sublinhar que nesse segundo modo possível de raciocínio apontado pelo autor nos estertores da década de 30 do século passado, não se fala em tolerância, intolerância ou intolerável, para lembrar o texto de Paul Ricœur (1995) que, em outra oportunidade, serviu de ponto de partida para que eu pudesse trabalhar, em outro contexto, a ideia de ordem pública. ${ }^{2}$

Hélène Gaudemet-Tallon, a quem fui apresentado em setembro de 2016, num colóquio em Paris sobre Controle de Constitucionalidade da lei estrangeira em que tive a honra de intervir (MONACO, 2017) e ao qual ela assistia, falando ainda em valores fundamentais do foro, introduz, todavia, a ideia de se respeitar a cultura estrangeira que aquela legislação exprime. E invocando o Raskolnikov de Crime e Castigo e seus dramas psicológicos, Gaudemet-Tallon (2005, p. 408) nos adverte de que nenhuma cultura - por mais aberta às diferenças que seja (acrescentaria eu) - poderá admitir o "tudo é permitido" que Dostoiévski (2018) introjeta na personagem naquele conhecido contexto em que a certeza da inexistência de Deus levaria à permissão de se agir de qualquer modo.

Pode-se ler em Le pluralisme en droit international privé: richesses et faiblesses, publicado em 2005, que ao mesmo tempo em que devemos ser tolerantes para com as diferenças do outro ordenamento, sob pena de se negar a razão de ser do Direito Internacional Privado, é essencial, por vezes, sermos intolerantes relativamente às afrontas

Tratava-se da redação da tese com a qual logrei obter, naquele mesmo Salão Nobre, exatos seis anos antes, o título de livre-docente. 
aos valores essenciais do foro. (GAUDEMET-TALLON, 2005, p. 408). Tenho para mim que é, sim, preciso ser intolerante, mas tão somente com o que se mostra intolerável de ser experimentado na sociedade do foro, que é o abjeto de que fala Ricœur.

Quero procurar destacar três aspectos sobre os quais, em continuação, nos debruçaremos nos próximos minutos: a excepcionalidade, o conteúdo e o alcance da noção de ordem pública internacional. Todos se imbricam como procurarei demonstrar.

Dizer que a ordem pública é excepcional é reconhecer que a ela não se deve recorrer cotidianamente. Se assim se faz; se se age não no extremo do "tudo é permitido" das angústias de Raskolnikov, mas no extremo oposto, o extremo do "tudo é proibido", de que tudo que vem de outra cultura ou de outro modo de pensar os problemas da vida humana em sociedade nos assusta; no extremo nacionalista e lexforista em que se interdita no foro a incidência de qualquer lei estrangeira pelo simples fato de ela apresentar diferenças, estaremos diante de outra coisa, mas nunca de uma exceção.

Uma importante consequência desse caráter exceptivo da ordem pública (MACHADO, 1960, p. 337) é a de que ela deve atuar de modo mínimo, preservando ao máximo a legislação estrangeira a ser aplicada ou dando a maior efetividade possível aos direitos ou às situações jurídicas constituídos no exterior. Trata-se, como sublinham Jacques Foyer (2008, p. 192) em artigo publicado nos Archives de Philosophie du Droit, de 2008, e Rui Manuel Moura Ramos (1998a, p. 111), em relatório publicado dez anos antes em Documentação e Direito Comparado, de uma consequência da igualdade de tratamento que deve ser dispensada à lei do foro e às leis estrangeiras potencialmente aplicáveis. Daí uma das conclusões a que chegarei: a de que é a ordem pública em sentido estrito aquela que deve ser fomentada nos dias atuais.

1. A ordem pública internacional em sentido amplo

Repare-se que até aqui eu me referi ou à ordem pública ou à ordem pública internacional, sem explicitar seu conteúdo ou a sua natureza. Não indiquei se a tenho por uma regra ou por um princípio, nem se entendo que no conceito caiba alguma identificação com o Direito Público, com a soberania, com os bons costumes. Procurarei responder a essas questões mais adiante.

Por ora, gostaria de me ater ao conteúdo da noção mesma da ordem pública internacional como imagino que o programa da disciplina tenha querido a ela se referir e que é o modo como tenho desenvolvido tal ponto ao longo dos últimos anos.

Se a ordem pública fosse um continente, no sentido de algo apto a conter alguma coisa, esse conteúdo seriam os valores fundamentais do foro. ${ }^{3}$ Mais precisamente,

Como deflui da leitura de Casella (2003, v. 98). 
valores fundamentais da sociedade do foro. Com isso quero afirmar que a ordem pública tal como eu a entendo antecede a estatuição do direito positivo e é capaz de redirecionar o ordenamento constantemente. Esse conjunto de valores da sociedade vincula-se, assim, não com o ordenamento em si, mas, antes, com a moral, com a economia, com a religião, com a ética desse grupamento humano politicamente organizado. Digo que a ordem pública antecede o direito positivo porque as normas nacionais plasmam tais valores no texto das leis, cristalizando-os. Luiz Olavo Baptista (2001, p. 96), menciona não apenas que a ordem pública antecede às normas escritas, mas que é, além do mais, o fundamento da ordem jurídica. Tal afirmação pode criar algumas dificuldades, pois a ordem pública seria, a um só tempo, fundamento e mecanismo de calibração do ordenamento, para usar uma expressão de Tércio Sampaio Ferraz Junior (2003).

Digo, ainda, que a ordem pública redireciona o direito posto por ser ela a mola propulsora de uma constante atualização hermenêutica, de que devem cuidar os magistrados, atentos ao modo pelo qual tais valores se movimentam numa ou noutra direção. Obviamente, eu poderia ter dito que esse redirecionamento decorreria na medida em que tais valores evoluam ou regridam. No entanto, tais palavras trazem em si mesmas uma conotação pré-ordenada que nem sempre é absoluta no sentido de que não haja, relativamente a todos os aspectos da vida em sociedade, uma única direção necessária e obrigatória para se caminhar, muito embora possa existir tal direção única com relação a alguns desses aspectos (pense-se, por exemplo, na ideia de não retrocesso).

Jacob Dolinger (1979, p. XII), na Introdução à tese com a qual logrou obter a titularidade de Direito Internacional Privado na Universidade do Estado do Rio de Janeiro, informa que o Poder Judiciário e a jurisprudência são, a um só tempo, a força protetora dos valores fundamentais da sociedade, como são a força "propulsora de sua evolução para o futuro, chegando, às vezes, a inspirar a reforma da legislação para sanar aspectos insolúveis da ordem pública". Daí porque - como apontaram Paul Graulich (1961, p. 164) e Jacob Dolinger (1979, p. XIV), não seja a ordem pública um fator perturbador, mas antes um fator conciliador.

Disso decorre que esses valores fundamentais que compõem a ordem pública podem estar em potencial e constante modificação. Embora se possa afirmar que os valores não sejam estanques e sempre se modifiquem, é inegável que, por vezes, essa modificação pode se dar em tão baixa velocidade, que a lentidão das mudanças pode dar à população a sensação verdadeira (pelo menos para o espaço de uma geração) de que nada se modificou.

Além disso, é importante frisar que é possível imaginar diversas formas pelas quais esses valores se manifestam na sociedade e que em cada uma dessas formas de manifestação os valores fundamentais assumam uma dada característica a fim de atingir um mesmo ou diversos desideratos. 
Se assim é, como me parece que seja, então eu ousaria dizer que a ordem pública a que se refere especialmente o Programa da Disciplina, onde se espera certo grau de completude e análise sistemática a respeito de um tema, é uma ordem pública em sentido amplo e que se manifestaria de três diferentes maneiras, pelo menos. Minha proposta, assim, é a de analisar brevemente dois desses modos de manifestação dos valores fundamentais de uma dada sociedade para então me concentrar na terceira forma - à qual chamarei, por tradição e oposição, de ordem pública em sentido estrito. Não tratarei, todavia, de uma quarta forma possível de manifestação desses valores, e que chamei, em minha tese de livre-docência, de controle intrínseco da constitucionalidade da lei estrangeira. (MONACO, 2013). Lá, procurei demonstrar que não obstante certa redundância com a ordem pública em sentido estrito há motivos suficientes para justificar sua incidência e análise pelo agente público que aplicou ou deixou de aplicar a lei estrangeira, especialmente como forma de controle de certa subjetividade com a qual ele possa ter atuado e que é de todo indesejável no trato da ordem pública.

Essa proposta nada mais é que uma tentativa de justificar a nomenclatura que consta do ponto. Para justificá-la, seja-me permitido abrir um parêntese: embora em Portugal a referência à ordem pública internacional seja pacífica na legislação, na doutrina e na jurisprudência, ${ }^{4}$ o fato é que, no Brasil, o que corresponde a essa ordem pública internacional é a assim chamada ordem pública que incide em segundo e em terceiro graus, para usar a terminologia de Jacob Dolinger. ${ }^{5}$ Justifico e deixo claro que utilizarei a gradação de níveis constante do Manual do autor que, a partir da $12^{\mathrm{a}}$ edição,

Como se depreende da leitura do capítulo IX, $\S \S 37^{\circ}$ a $39^{\circ}$ da tese de Moura Vicente (2001).

Em artigo escrito originalmente em inglês e que fora publicado, em 1982, na Texas International Law Journal, depois traduzido para o português, Dolinger se refere à ordem pública de segundo nível nos exatos termos em que a doutrina portuguesa se refere à ordem pública internacional (DOLINGER, 1986, v. 23). Como veremos mais adiante, trata-se da ordem pública que engloba tanto a recusa de incidência da lei estrangeira que produz resultados conflitantes com os valores fundamentais do foro, como também a recusa de reconhecer eficácia a direitos e situações jurídicas consolidadas no exterior a partir da incidência de uma lei estrangeira qualquer. $\mathrm{O}$ terceiro nível seria o da incidência da assim chamada ordem pública mundial ou verdadeiramente internacional. Nesse sentido, parece ter havido modificação do pensamento do autor relativamente aos graus de ordem pública como referenciados na já mencionada tese de titularidade junto à UERJ, em que, às fls. 41, pode-se conferir que o segundo e o terceiro graus tinham conteúdos distintos. Não obstante, em artigo subsequente (DOLINGER, 2004, v. 93), volta a modificar essa gradação, retornando à mesma gradação que usara em sua tese. Nesses dois textos, assim como no volume referente à Parte Geral do seu Direito Internacional Privado, o $2^{\circ}$ nível é reservado à recusa de aplicação no foro de uma lei estrangeira que produz resultados ofensivos, ao passo que o $3^{\circ}$ nível diz respeito à recusa de reconhecimento de um direito ou situação jurídica constituídos no exterior com base numa lei estrangeira qualquer, por afronta aos valores fundamentais do foro. Faço essa digressão porque em Parecer elaborado por Carmen Tiburcio e Luís Roberto Barroso, naquele interregno, tais autores se utilizaram da gradação contida no artigo de Jacob Dolinger que ambos traduziram para o português. Mencionado parecer está publicado em Tiburcio (2006, p. 365-407). 
foi enriquecido pela coautoria atribuída a Carmen Tiburcio e pela inserção da temática atinente ao processo internacional. (DOLINGER; TIBURCIO, 2016).

Os valores fundamentais de uma dada sociedade, assim, parecem constituir a aqui chamada ordem pública internacional em sentido amplo e operam, atuam, no âmbito jurídico, de quatro formas distintas, das quais sobre uma (controle intrínseco da constitucionalidade das leis estrangeiras) não direi nada além do que aquilo que acima ficou consignado.

1.1. A ordem pública internacional em manifestação material: as normas de aplicação imediata

Afastando-nos completamente da seara conflitual, iniciemos essa análise pelo campo do direito material. Pode o legislador do foro estabelecer as chamadas normas de aplicação necessária e imediata, ${ }^{6}$ que se configuram, segundo me parece, como o primeiro modo de garantir o resguardo dos valores fundamentais do foro por meio da incidência certa de uma norma material específica, sem que nos preocupemos com a designação de uma ou de outra das leis potencialmente aplicáveis pela incidência da norma de conflitos.

Nesses casos, o que o legislador do foro quer é submeter a situação plurilocalizada à incidência de uma norma material vigente naquele próprio ordenamento, e que resolverá a questão ex ante. Não se deixa, assim, espaço para que o agente público tergiverse sobre a incidência desta ou daquela lei, sobre o resguardo ou não deste ou daquele valor caro à sociedade do foro.

Muito embora não seja pacífico na doutrina, tenho para mim que as normas de aplicação necessária e imediata atuam a priori, impedindo a incidência do método conflitual e de qualquer indagação a respeito da lei aplicável. Nesse mesmo sentido, Rui Manuel Moura Ramos (1998b, p. 50-51), afirma que as normas de aplicação imediata

\footnotetext{
Phocion Francescakis, autor de origem grega a quem se deve a doutrina moderna das normas de aplicação imediata, alterou a nomenclatura do instituto ao longo de seus estudos. Assim, em 1958 (La théorie du renvoi et les conflits de systems en droit international privé. Paris: Sirey), chamou-as règles d'application immédiate. Em 1966 chamou atenção para o fato de ser o termo "improvisé et uniquement descriptif" (Quelques précisions sur les "lois d'application immédiate" et leurs rapports avec les règles de conflits de lois. Revue Critique de Droit International Privé. Paris, v. 55, n. 1, p. 1-18, jan./mar. 1966, p. 2 e 9). Em 1968, passou a utilizar a expressão lois de police, com a intenção manifesta de fundir num único conceito o conteúdo das expressões lois de police et de sûreté e lois d'ordre public (Répertoire de droit international. Verbete "Conflits de lois (príncipes généraux)". Paris: Dalloz, 1968, p. 470 et seq.). Por fim, em 1974 (Lois d'application immédiate et droit du travail: l'affaire du comité d'entreprise de la Compagnie des Wagonslits. Revue Critique de Droit International Privé, Paris, v. 63, n. 2, p. 273-296, avr./juin, 1974), voltaria a valer-se quer da expressão "leis de aplicação imediata", como de "leis de aplicação necessária".
} 
delimitam seu campo de aplicação sem levar em conta as determinações das regras de conflitos.

O legislador do foro constrói, assim, uma norma jurídica direta que pode ter por hipótese (i) a descrição de uma relação plurilocalizada (ex.: uma norma direta sobre adoção internacional ou sobre um contrato específico, como o de compra e venda internacional de mercadorias) ou (ii) a descrição de uma hipótese genérica, que abarque tanto casos eminentemente internos, nacionais, como casos plurilocalizados.

Não obstante, nesse segundo caso, tenho inúmeras dificuldades de aceitar a configuração destas normas como normas de aplicação necessária e imediata. E explico meu ponto de vista: a descrição de situações gerais e abstratas sem uma clara indicação de sua internacionalidade jogam por terra o caráter de excepcionalidade que me parece essencial demarcar no que tange à ordem pública em sentido amplo, sob pena de, em um ambiente totalitário, alguém afirmar que todas ou quase todas as normas materiais de um ordenamento sejam normas de aplicação necessária e imediata.

Não descarto, todavia, a possibilidade de seu reconhecimento em alguns casos, como o faz, por exemplo, em diversos escritos, Claudia Lima Marques (2011) relativamente a algumas das normas contidas no Código brasileiro de Defesa do Consumidor. Mas deixo consignada aqui minha predileção metodológica por resolver tais situações pela incidência da ordem pública em sentido estrito, ainda que, para isso, seja preciso sujeitar a situação à discricionariedade do agente público, que precisará, em consequência, ser controlada.

É que a invocação ou não da ordem pública em sentido estrito depende $d a$ percepção do magistrado, do árbitro ou do tabelião de que o conteúdo da lei estrangeira mandada aplicar pela regra de conflitos produz resultados que violam os valores fundamentais do foro, havendo, aqui, clara discricionariedade, como frisou Phocion Francescakis (1958, p. 37). Essa discricionariedade pode ser controlada por meio dos recursos judiciais cabíveis ou por provocação dos órgãos de correição.

Por fim, quanto a esta modalidade, é preciso reconhecer que, por vezes, normas de aplicação necessária e imediata estrangeiras poderão se impor ao magistrado do foro. Nesse ponto, desde que seu conteúdo não colida diretamente com a ordem pública em sentido estrito do foro, parece-me, com base nos ensinamentos de Bernard Audit (2003, p. 282) e, antes dele, no artigo de Pierre Mayer (2015), que se deva ao menos tomá-las em consideração, ainda que aquele ordenamento não seja o indicado pelas regras de conflitos do foro.

Constatamos isso claramente, uma de minhas orientandas e eu, em sua tese de doutorado (DALLARI, 2019) com relação às normas estadunidenses que regem a aprovação de novos medicamentos durante as pesquisas clínicas multicêntricas com seres humanos. In casu, não nos pareceu haver ofensa à ordem pública brasileira, pois as 
normas deontológicas nacionais resguardam os interesses dos participantes da pesquisa e convivem com as regras procedimentais da legislação estrangeira que garantirão a segurança do mercado consumidor.

1.2. A construção de normas de conflito de leis no espaço com conexões alternativas e axiologicamente orientadas

O segundo modo de atuação dos valores fundamentais do foro vincula-se com a própria construção das normas de conflito.

Dolinger nos lembra de que o legislador tem sempre em vista razões de natureza conflitual ao escolher os elementos de conexão para cada conceito-quadro, ainda quando esta conexão leve à incidência da lei material do foro. Ou seja, não é nem o territorialismo nem o lexforismo que o movem. Como se pode depreender da tese apresentada por Carmen Tiburcio para o concurso que a escolheu como sucessora de Jacob Dolinger na titularidade da disciplina na UERJ, a conjugação operada pelo legislador entre o forum rei sitae e a lex rei sitae visa não apenas a efetividade da decisão, mas, principalmente, a segurança para as partes. (TIBURCIO, 2016, p. 77).

Em suma, ao escolher a conexão o legislador do Direito dos conflitos tem em vista a lei mais próxima e não os valores fundamentais do foro.

Pois a segunda maneira de defender os valores fundamentais da sociedade do foro passa pela construção de normas de conflitos que preveem conexões alternativas com o claro intuito de alcançar um específico resultado material (proteger um grupo tido como vulnerável, como as crianças, por exemplo). Assim, a norma que estabelece conexões alternativas está já impregnada pelos valores que o foro visa realizar. E consequentemente, diminui-se a esfera de incidência possível da ordem pública em sentido estrito.

Como afirma Paolo Picone (1999, p. 114-118), a valoração de caráter material que se exprime por meio de conexões alternativas comporta uma modificação na atuação dos mecanismos clássicos de Direito Internacional Privado, dentre os quais se encontra a ordem pública internacional.

Com outro viés, mas chegando às mesmas consequências, lembre-se o saudoso professor australiano Peter Nygh (1995, p. 379), que no curso publicado no Recueil, em 1995, afirmou que quanto mais rígidas forem as regras de determinação da lei aplicável, maior o espaço para que válvulas de escape como a ordem pública em sentido estrito possam atuar.

Um exemplo está na determinação da lei aplicável em matéria de sucessão mortis causa no Brasil. Essa norma de conflitos se desdobra numa infinidade de problemas que vou me escusar de tratar aqui, remetendo o leitor para outras fontes. (MONACO, 2005; MONACO, 2004). Quero salientar, desde logo, que essa regra tem um intuito claro: 
beneficiar o cônjuge sobrevivente ou os filhos do de cujus, mas apenas se forem brasileiros. Se forem estrangeiros, não há conexão alternativa. Se o último domicílio estivesse fixado no Brasil, não há conexão alternativa, pois a alternatividade atinge justamente a lei do último domicílio do morto e a lex fori. Mas se o último domicílio era no exterior e um dos herdeiros mencionados for brasileiro, o juiz deverá comparar a lei estrangeira e a do foro e aplicar aquela que traga maiores benefícios para o herdeiro brasileiro. Vamos imaginar que a legislação vigente no local do último domicílio não conheça a legítima, aquela parcela do patrimônio a respeito da qual o titular não pode dispor em testamento. E vamos imaginar que o falecido, viúvo e pai de um único filho de nacionalidade brasileira, tivesse deixado um testamento (válido segundo a lei do local de sua facção) que dispusesse o seguinte: "deixo a parte disponível do meu patrimônio para o meu irmão". Se o juiz aplicar a lei estrangeira, 100\% do patrimônio deveria ser entregue para o irmão do morto, deixando desassistido o filho brasileiro. Ao aplicar a lei brasileira, 50\% do patrimônio seria deferido ao irmão do morto e $50 \%$ a seu filho, que a lei brasileira considera, como se sabe, herdeiro necessário.

Eu não tenho a menor sombra de dúvidas de que seria possível atingir o mesmo resultado nesse caso concreto se recorrêssemos à ordem pública para afastar a lei estrangeira que não garante a reserva da legítima. E mais, se o recurso fosse à ordem pública, seria possível defender todos os descendentes (e não só os filhos), os ascendentes e o cônjuge ou companheiro supérstites, independentemente de suas nacionalidades, tratando igualmente os herdeiros estrangeiros e os herdeiros nacionais.

Ao estatuir uma conexão alternativa que visa realizar um resultado material determinado, o legislador vincula o agente público de modo um pouco mais intenso, diminuindo o espaço para sua atuação discricionária, o que me parece positivo.

1.3. O princípio da ordem pública ou a exceção de ordem pública internacional em sentido estrito

Passemos, agora, à terceira modalidade de realização dos valores fundamentais do foro. Trata-se do princípio da ordem pública ou da ordem pública internacional em sentido estrito.

Adianto, desde logo, que no meu modo de ver, a ordem pública em sentido estrito é um princípio e não uma regra. Logo, concordo com a doutrina que defende ser impossível reconhecer a existência de normas de ordem pública. Como salienta Dolinger (1979, p. 40-41), “não sendo as leis propriamente ditas de ordem pública, não há como falar de leis de ordem pública interna e leis de ordem pública externa. Existe o princípio da ordem pública, algo abstrato que é aplicado às leis quando o juiz entender que determinada regra jurídica deve contar com a proteção, com o reforço desse princípio”. 
Como consequência, não me parece adequado afirmar, como já se afirmou no passado, que haja identificação da ordem pública com toda e qualquer norma de direito público. Há ordem pública que exala das normas de direito público, porquanto impregnadas pelo princípio, como há ordem pública que exala de normas de direito privado, porque também estas tenham sido impregnadas pelo princípio.

A identificação dessa impregnação pelo princípio é, sobretudo, contemporânea, no sentido de que a variabilidade dos valores fundamentais da sociedade permitirá reconhecer como embebida na ordem pública regras nas quais não se via anteriormente essa impregnação, da mesma forma que regras antes revestidas desse qualificativo podem perder esse caráter.

Lembro-me, a propósito, de que, quando comecei a ministrar aulas em cursos de graduação em outras instituições de ensino, apresentava a meus alunos uma situação em que dois homens ou duas mulheres que mantinham uma vida afetiva em comum e domiciliados nos Países Baixos, apresentavam-se perante o judiciário brasileiro para pleitear adoção conjunta de uma ou mais crianças. Indagados, metade da sala dizia que afastaria a lei estrangeira concessiva da capacidade para adotar conjuntamente por entendê-la ofensiva aos valores vigentes no foro. Outra metade dizia que não, que pessoas nesta mesma condição e domiciliadas no Brasil eram tidas pela legislação brasileira como capazes de adotar singularmente, e que as crianças seriam acolhidas por ambos os membros do casal. Que tal circunstância provaria que a situação não era ofensiva à ordem pública, porquanto os efeitos se verificassem no Brasil. Minha intenção ao fazer a pergunta era demonstrar que no mesmo metro quadrado onde se encontrava aquele aluno ou aquela aluna havia outra pessoa tão vinculada aos valores da sociedade brasileira como ele ou ela e que essa outra pessoa pensava diferentemente dela.

Esse exemplo nos coloca uma série de desafios no trato da ordem pública e foi crucial em minha formação como docente para ressaltar, no ensino do princípio da ordem pública, o modo pelo qual o princípio é manejado, quem são os atores que o manejam e quais as finalidades que se visam alcançar com seu manejo e que atingem situações relevantes para o jurisdicionado.

Pois são justamente esses os méritos que se pode encontrar na obra de Jacob Dolinger e que foram tão bem ressaltados pelo Titular de Direito Internacional Privado desta Casa, Professor João Grandino Rodas (1993, p. 76), em seu Direito internacional privado brasileiro, ao se referir ao pensamento de seu colega da universidade fluminense: "Dolinger, com grande lucidez explanou que o princípio da ordem pública tem aplicação diferente em três níveis, que seguem uma gradação crescente, na incidência de sua aplicação". Adaptando um pouco o texto, eu diria que o princípio da ordem pública pode se amalgamar em três diferentes densidades conforme a finalidade que desempenhem 
na proteção daqueles mesmos valores fundamentais da sociedade do foro. Duas dessas densidades interessam o Direito Internacional Privado, uma interessa ao direito em geral. Assim, de acordo com essa formulação doutrinária, no primeiro nível a ordem pública em sentido estrito é manejada na construção contemporânea das normas jurídicas internas de um ordenamento. Quem a maneja, é o legislador, quando as estatui, ou o agente público competente, quando a aplica. É importante frisar que o legislador não tem outro compromisso que não o de produzir normas, traduzindo em regras aqueles valores fundamentais da sociedade do foro. Descompromissado e não necessariamente versado em Direito, esse legislador maneja a ordem pública com certo grau de superficialidade.

Ao descrever hipóteses e consequências queridas por aquele povo, o legislador deixa pistas aos juristas que vão, posteriormente, dizer se se trata de instituições ou situações típicas do direito público, onde a vontade das partes é quase sempre absolutamente irrelevante (como no Direito Penal, em que a vontade da vítima de um homicídio tentado de perdoar o autor do delito é incapaz de impedir o Estado de aplicarlhe a pena), ou de direito privado, onde há o domínio da autonomia da vontade de se dar gênese à relação juridicamente relevante, já que ninguém nos obriga a casar, testar, contratar, adquirir imóveis etc.

Mas na descrição das situações de direito privado, o legislador nos outorga ou nos retira ainda o espaço por meio do qual se manifestará outra vontade, de cariz regulatório, quando então se modificam os efeitos e as consequências estabelecidos de modo meramente supletivo na norma, para prevalecer a vontade manifestada pelas partes, sendo esse o fundamento da distinção entre negócios jurídicos e atos jurídicos em sentido estrito.

Todavia, dada a contemporaneidade do princípio, é possível que se altere o caráter cogente de algumas dessas normas. Em tais casos, não foi a lei que mudou, mas a ordem pública que a permeia que sofreu alteração ditada pelas necessidades sociais.

Daí a relevância do Judiciário e da Jurisprudência na adequação dos valores fundamentais da sociedade do foro à ação do tempo, de que são exemplo as decisões do Supremo Tribunal Federal que fixaram a possibilidade de se reconhecer como tais as famílias formadas por pessoas de mesmo sexo que passaram, assim, a se unir em casamento ou em união estável, muito embora o direito positivo não tenha sido alterado.

A finalidade do legislador ao manejar o princípio para estatuir normas jurídicas e a do julgador ao reinterpretá-las à luz dos valores contemporâneos é a de atribuir ao jurisdicionado uma maior ou menor autonomia privada, portanto.

Mas também pode o Judiciário atuar de outro modo, em razão de um choque de culturas que vicejam em um mesmo espaço.

Em 27 de dezembro de 2018, na cidade de Santo Antonio de Jesus, no Recôncavo Baiano, falecia a Ialorixá e membro da Academia Baiana de Letras, Mãe Stella 
de Oxóssi. A Ialorixá é uma sacerdotisa do Candomblé, religião de matriz africana, que se encarrega, por indicação dos Orixás, suas Divindades, das obrigações religiosas de um terreiro, seu templo. No caso, o Ilê Axé Opô Afonjá, unidade mantida em Salvador. A cultura religiosa determina que o sepultamento de uma Ialorixá seja seguido de rituais que se estendem por um ano e se repetem mesmo depois, de tempos em tempos, o Axexé. Após um derrame, mãe Stella se afastou do Terreiro e foi viver no interior da Bahia com sua companheira. À falta de um codicilo ou outro documento hábil que descrevesse a cerimônia de sepultamento, a companheira de mãe Stella decidiu enterrá-la na cidade de Nazaré das Farinhas.

Diante disso, a associação civil Sociedade Cruz Santa do Axé Opô Afonjá, que mantém o Terreiro, ingressou com uma Ação de Obrigação de Fazer cumulada com Tutela de Urgência para transferência do cadáver de Mãe Stella da cidade de Nazaré das Farinhas para ser velado na área do Ilê Axé. Por sua vez, o sobrinho de mãe Stella intentou outra ação visando impedir o sepultamento do corpo da tia no cemitério Nosso Senhor dos Aflitos, na cidade de Nazaré.

A juíza de Direito plantonista da Comarca de Nazaré, ouvido o Ministério Público, deferiu a tutela de urgência citando Lévi-Strauss, por entender que entre o direito de personalidade que, em razão do falecimento, deveria ser exercido pela companheira da falecida e a liberdade de culto e da tutela do patrimônio cultural, estes deveriam prevalecer. (BRASIL, 2018).

Esses fatos caracterizam-se como fatos eminentemente internos em que não havia nenhum conflito de leis, especialmente porque o ordenamento brasileiro não se caracteriza como um ordenamento plurilegislativo, malgrado a forma federativa de nosso Estado.

Tratou-se, em verdade, de uma situação em que o Judiciário brasileiro foi chamado a atuar a ordem pública e os valores que ela representa para dirimir um conflito de culturas e, por isso, achei que caberia a menção nessa prova de erudição, tendo em consideração as funções desempenhadas pelo Direito Internacional Privado. Direito Internacional Privado esse que soluciona conflitos de culturas, como descreveu Erik Jayme, autor a quem se atribui, no Brasil, segundo quer me parecer, coisas que ele não escreveu ou sentidos que não são exatamente os que defluem da leitura de seu cursos e conferências na Academia da Haia. ${ }^{7}$

No segundo nível, por sua vez, essa ordem pública ganha contornos internacionais e é manejada na análise dos resultados que uma lei estrangeira qualquer

Em especial a respeito do que vai no texto, veja-se Jayme (1995, v. 251). 
pode desencadear se for aplicada no foro, conforme determina a norma de conflitos respectiva.

Dolinger (2007, p. 544) salienta que "a lei que choca, que é incompatível, que escandaliza, esta lei é distante, foge completamente da idéia básica de proximidade, e por isto, não pode ser aplicada". Não obstante, e com todo o respeito que merece o autor, creio que essa passagem ficaria mais adequada se nós a lêssemos dando ênfase não à diferença decorrente da lei, mas, sim, dos efeitos que ela pode produzir: [os efeitos que chocam, que são incompatíveis, que escandalizam, tais efeitos são distantes, fogem completamente da ideia básica de proximidade, e por isso, não podem ser resguardados].

Nesse sentido, o caso Patiño, decidido pela Corte de Cassação francesa (ANCEL; LEQUETTE, 2006, p. 330-348), que se configurou como um romance políticojurídico (Paul Lagarde, na Revue Critique de 1964, p. 535) um imbróglio jurídico extraordinário (Phillipe Malaurie, no Clunet de 1963, p. 1.020).

Maria Cristina de Bourbon y Brosch-Labrus, duquesa de Durcal, de nacionalidade espanhola, casou-se com Antenor Patiño Rodriguez, empresário de nacionalidade boliviana, na cidade de Madrid, adquirindo a nacionalidade boliviana. Fixaram domicílio em Paris, modificando-o, durante a II Guerra, para Nova York. O processo de divórcio tramitou na França, que atendendo a suas regras de conflito, determinou a aplicação da lei boliviana (nacionalidade comum do casal), que, por sua vez, reenviou a questão para a lei do local da celebração do casamento, ou seja, para a lei espanhola. O direito boliviano da época admitia o divórcio, mas apenas e tão somente se este fosse autorizado pela lei do local em que contraído o matrimônio. A lei espanhola, por sua vez, não admitia o divórcio, mas autorizava a separação de corpos, que era desconhecida do direito boliviano. Analisadas separada e abstratamente, nenhuma das leis seria, em princípio, ofensiva da ordem pública francesa da época. Mas sua observância concomitante decorrente do reenvio parcial feito pela lei boliviana à lei espanhola, teria por efeito impedir o desfazimento da vida em comum. Trata-se de um caso clássico e que demonstra bem que o que se visa com a ordem pública é evitar os efeitos contrários aos valores fundamentais da sociedade do foro.

$\mathrm{O}$ direito positivo brasileiro menciona a ordem pública, os bons costumes e a soberania nacional (LINDB, art. 17). A menção aos bons costumes e à soberania ao lado da ordem pública mereceu elogios de Haroldo Valladão (1970, p. 502), para quem essa tríade representaria a fórmula brasileira da ordem pública. Por outro lado, foi objeto de críticas da parte de Amilcar de Castro (1997, p. 291), para quem as menções são 
desnecessárias na medida em que trazem uma distinção puramente verbal, insuficiente, desnecessária e inconveniente, pois seriam faces de um mesmo poliedro: a ordem social. ${ }^{8}$

No meu modo de ver, a mudança que caberia na legislação brasileira vigente seria a de dar proeminência exclusiva ao princípio jurídico da ordem pública, extirpando da legislação valores outros como a soberania nacional e os bons costumes, que são sempre manipuláveis, mormente em regimes políticos de exceção. Nesse sentido, aliás, o Anteprojeto da década de 1990: “As leis, atos públicos e privados, bem como as sentenças de outro país, não terão eficácia no Brasil se forem contrários à ordem pública brasileira".

Quem a maneja, é o juiz, o árbitro ou o tabelião e sua incidência frusta uma legítima expectativa de direito das partes: a de verem sua situação jurídica transformada pela incidência da norma estrangeira mandada aplicar pela norma de conflito. Todavia, essa expectativa é frustrada na medida em que essa lei é parcial ou integralmente mutilada.

Também nesse segundo nível, o princípio da ordem pública pode tornar-se maleável e mutável com o transcorrer do tempo. Assim, situações que, no passado, não conflitavam com nosso conceito de ordem pública, podem ocasionar tais efeitos amanhã ou vice-versa. Um exemplo é a determinação do guardião em razão do sexo das crianças e dos pais, que já foi conforme à ordem pública brasileira e já de há muito não o é mais. (MONACO, 2012).

Ainda no segundo nível, é imperioso que averiguemos a função que a proximidade desempenha nessa análise em concreto da incidência do princípio da ordem pública. Hélène Gaudemet-Tallon (2005, p. 425) nos lembra de que foi Franz Kahn o primeiro a defender a Inlandbeziehung.

Segundo essa técnica, se o que justifica a intervenção da ordem pública para afastar a lei estrangeira é a perturbação que esta última pode causar na integridade daquele sistema social, só seria possível fazê-la atuar se o caso concreto possuísse intensos laços com aquele foro.

Obviamente, o mais difícil nessa seara é justamente determinar os critérios para a indicação dos liames úteis para caracterizar essa proximidade e não irei, no escasso tempo de que disponho, me ater a essa questão.

Hans Lewald (1939, p. 124) cita duas decisões da Corte Suprema dos Países Baixos (Hooge Raad), ambas publicadas em 13 de março de 1936 e que versaram sobre medidas de instituições bancárias daquele estado que, com base na Joint Resolution americana, emitiram títulos reembolsáveis a partir do valor diário do dólar-ouro. Uma

Situação semelhante ocorreu na Itália. Betti (1956, p. 282), festejava a menção dos bons costumes ao lado da ordem pública no art. 31 das disposições preliminares do Código Civil. Por sua vez, Pocar (2002, p. 43-44) aprova a redação do art. 16 da nova lei, que extirpou os bons costumes do texto legal. 
das instituições autorizava o resgate exclusivamente nos Estados Unidos, ao passo que a outra introduziu uma cláusula de opção para que os credores pudessem resgatar seus créditos em Amsterdam com base na cotação do dólar-ouro do dia. Para aquilo que aqui nos interessa, foi justamente essa cláusula que fez com que a decisão relativa a essa instituição financeira fosse tomada com o afastamento da norma americana por ofensa à ordem pública neerlandesa. No outro caso, por não haver a possibilidade da produção de efeitos diretos nos Países Baixos, a corte entendeu adequada a decisão da instância inferior que foi tomada com base na aplicação da lei americana.

No terceiro nível, salienta Dolinger (1979, p. 42), em sua tese, “em grau de natureza gravíssima, a ordem pública irá ao ponto de impedir a aceitação no foro de situações já consumadas e consagradas no exterior".

Por atingir situações consolidadas no exterior, a ordem pública incide aqui de maneira atenuada, em um número menor de hipóteses. Encontrada pela primeira vez no caso Bulkley, decidido pela Corte de Cassação francesa, em 1860 (ANCEL; LEQUETTE, 2006, p. 30-38), a expressão denota um adensamento maior do princípio que faz com ele incida numa área menor do plano das situações da vida e que sua maior densidade permita barrar o exercício de tais direitos.

Também aqui fluida e maleável no tempo, a ordem pública deve ser averiguada em sua contemporaneidade, o que explica que divórcios obtidos antes de 1977 no exterior tenham sido, depois da mudança da legislação, reconhecidos pelo Supremo Tribunal Federal.

Quem se encarrega de manter coesa essa mais densa manifestação dos valores fundamentais do foro é, no direito brasileiro, desde a Emenda Constitucional n. 45/2004, o Superior Tribunal de Justiça.

Conclusão

Vistos os três níveis de incidência da ordem pública em sentido estrito, é chegada a hora de avançar na tentativa de lhe delimitar certo conteúdo substancial.

Parece-me inegável que a Constituição do foro mereça ser vista como um de seus focos irradiadores - donde me advém a dificuldade de aceitar o raciocínio de Luiz Olavo Baptista (2001, p. 96), de que a ordem pública seja o fundamento da ordem jurídica.

Em verdade, acredito que devam ser as normas constitucionais seu principal molde. Mas não pode ser só essa a conformação substancial do princípio. Como salientou Luís Roberto Barroso (2010, p. 51), a exogenia da ordem pública relativamente às leis traz como consequência a percepção de que "aspectos inerentes à ordem pública" sejam encontráveis “fora do texto constitucional. Será possível, assim, negar aplicação à norma 
estrangeira por afronta à ordem pública brasileira, mesmo que ela não se confronte, direta ou indiretamente, com a Constituição".

Nesse cenário, também o Direito Penal, por sua propalada função de ultima ratio do ordenamento jurídico, de forma normativa excepcional a incidir para a regulação das relações sociais, procurando impedir o que a sociedade não tolera na conduta humana mostra-se um conveniente limite para a ordem pública, inclusive porque, como afirma Ana Elisa Libertore Bechara (2017, p. 20), “a questão penal é um problema eminentemente político".

Da mesma forma, disposições ordinárias de natureza civil, empresarial, trabalhista, não podem ser alijadas a priori, de sua modelagem.

Trata-se de buscar bons parâmetros para a modelagem contemporânea do princípio da ordem pública ou dessa ordem pública em sentido estrito e que é, afinal a ordem pública com a qual estamos habituados no Direito Internacional Privado.

Essa ordem pública que não se define, essa ordem pública que não se sabe, com certeza qual seja seu conteúdo, mas que na situação concreta é capaz de atuar sem qualquer piedade na defesa dos valores fundamentais da sociedade. Daí porque não possa concordar com Erik Jayme (1995, p. 225) quando afirmou que as questões pessoais, de Direito de Família e de Direito das Sucessões devam ser defendidas pela intervenção da ordem pública, enquanto que questões relativas a obrigações contratuais teriam sua defesa a partir das normas de aplicação imediata. Trata-se de mecanismos de defesa que podem ser usados para uma ou outra matéria, a depender das circunstâncias. ${ }^{9}$

Ordem pública que não pode ser modelada a partir dos critérios, dos preconceitos-, das preconcepções individuais de quem se encarrega de lhe dar vazão, mas que deve, antes, ser o instrumento para a defesa e a manifestação dos valores de toda a sociedade. Daí a vigilância acerca da discricionariedade em seu manejo.

Ordem pública que não cansa de incidir, quando é necessário que ela incida, atenta a sua própria excepcionalidade, inclusive e especialmente na defesa dos direitos fundamentais ou dos direitos humanos, estejamos em que tempo estivermos, governe-nos o governo que nos governar.

Muito obrigado.

São Paulo, 23 de janeiro de 2019. (revisto em 02/03/2019).

Parece caminhar nesse sentido, também, Dario Moura Vicente, quando afirma: “o regime dos contratos obrigacionais, por exemplo, compreende entre nós múltiplas normas que exprimem princípios éticojurídicos do maior relevo, os quais integram a noção de ordem pública”. (VICENTE, 2012, p. 332). 


\section{Referências}

ANCEL, Bertrand; LEQUETTE, Yves. Les grands arrêts de la jurisprudence française de droit international privé. 5. ed. Paris: Dalloz, 2006.

AUDIT, Bernard. Le droit international privé en quête d'universalité: cours général. Recueil des Cours, Leiden/Boston, v. 305, p. 9-488, 2003.

BAPTISTA, Luiz Olavo. O direito estrangeiro nos tribunais brasileiros. Revista Forense: doutrina, legislação e jurisprudência, Rio de Janeiro, v. 97, n. 355, p. 89-99, maio/jun. 2001.

BARROSO, Luís Roberto. Interpretação e aplicação da constituição: fundamentos de uma dogmática constitucional transformadora. 7. ed., 2. tir., São Paulo: Saraiva, 2010.

BECHARA, Ana Elisa Liberatore Silva. Valor, norma e injusto penal: considerações sobre os elementos normativos do tipo objetivo no direito penal contemporâneo. Tese (Titular) - Faculdade de Direito, Universidade de São Paulo, São Paulo, 2017.

BETTI, Emilio. Problematica del diritto internazionale. Milano: Giuffrè, 1956.

BRASIL. Tribunal de Justiça da Bahia. Processos n. 8000796-64.2018.8.05.0176 e 800079749.2018.8.05.0176. Nazaré, dez. 2018. Disponível em: https://www.cartacapital.com.br/wpcontent/uploads/2018/12/PLANTA\%CC\%83_O_mA\%CC\%83\%C2\%A3e-stella-1-1.pdf. Acesso em: 2 mar. 2019.

CASELLA, Paulo Borba. A ordem pública e a execução de cartas rogatórias no Brasil. Revista da Faculdade de Direito da Universidade de São Paulo, São Paulo, v. 98, p. 564-571, jan./dez. 2003.

CASTRO, Amílcar de. Direito internacional privado. 5. ed. atual. Rio de Janeiro: Forense, 1997.

CONFLITS de lois (príncipes généraux). In: FRANCESCAKIS, Phocion. Répertoire de droit international. Paris: Dalloz, 1968.

DALLARI, Analluza Bolivar. O balizamento do contrato de pesquisa clínica pelas normas de aplicação imediata brasileiras. Orientador: Gustavo Ferraz de Campos Monaco. Tese (Doutorado) - Faculdade de Direito, Universidade de São Paulo, São Paulo, 2019.

DOLINGER, Jacob. A evolução da ordem pública no direito internacional privado. Tese (Cátedra) - Faculdade de Direito, Universidade do Estado do Rio de Janeiro, Rio de Janeiro, 1979.

. A ordem pública internacional em seus diversos patamares. Revista dos Tribunais, São Paulo, v. 93, n. 828, p. 33-42, out. 2004.

. Direito internacional privado: contratos e obrigações no direito internacional privado. Rio de Janeiro: Renovar, 2007.

- Ordem pública mundial: ordem pública verdadeiramente internacional no direito internacional privado. Revista de Informação Legislativa, Brasília, v. 23, n. 90, p. 205-233, abr./ jun. 1986. 
DOLINGER, Jacob; TIBURCIO, Carmen. Direito internacional privado: parte geral e processo internacional. 12. ed, rev., atual. e ampl. Rio de Janeiro: Forense, 2016.

DOSTOIÉVSKI, Fiódor. Crime e castigo = Prestuplênie i nakazánie. Tradução Paulo Bezerra. 7. ed., 1. reimp. São Paulo: Editora 34, 2018.

FERRAZ JÚNIOR, Tércio Sampaio. Introdução ao estudo do direito: técnica, decisão, dominação. 4. ed., revista e ampliada, São Paulo: Atlas, 2003.

FOYER, Jacques. L`égalité en droit international privé. Archives de Philosophie du Droit, Paris, v. 51, p. 179-193, 2008.

FRANCESCAKIS, Phocion. La théorie du renvoi et les conflits de systèms en droit international privé. Paris: Sirey, 1958.

. Lois d'application immédiate et droit du travail: l'affaire du comité d'entreprise de la Compagnie des Wagons-lits. Revue Critique de Droit International Privé, Paris, v. 63, n. 2, p. $273-$ 296, avr./juin, 1974.

. Quelques précisions sur les "lois d'application immédiate" et leurs rapports avec les règles de conflits de lois. Revue Critique de Droit International Privé, Paris, v. 55, n. 1, p. 1-18, jan./mar. 1966.

GAUDEMET-TALLON, Hélène. Le pluralisme en droit international privé: richesses et faiblesses: (le funambule et l'arc-en-ciel) cours général. Recueil des Cours, Leiden, n. 312, p. 9-488, 2005.

GRAULICH, Paul: Principes de droit international privé: conflit de lois, conflit de juridictions. Paris: Dalloz, 1961.

JAYME, Erik. Identité culturelle et intégration: le droit international privé postmoderne: cours général de droit international privé. Recueil des Cours, Leiden, v. 251, p. 9-268, 1995.

LEWALD, Hans. Règles générales des conflits de lois: contribution à la technique du droit international privé. Recueil des Cours, Leyde, n. 69, p. 1-147, 1939.

MACHADO, João Baptista. Problemas na aplicação do direito estrangeiro, adaptação e substituição. Boletim da Faculdade de Direito, Coimbra, n. 36, p. 327-351, 1960.

MARQUES, Claudia Lima. Comércio eletrônico de consumo internacional: modelos de aplicação da lei mais favorável ao consumidor e do privilégio de foro. Revista do Advogado, São Paulo, a. 31, n. 114, p. 31-54, dez. 2011.

MAYER, Pierre. Les lois de police étrangères. In: MAYER, Pierre. Choix d'articles de Pierre Mayer. Paris: Librairie Générale de Droit et de Jurisprudence - L.G.D.J., 2015. p. 99-161.

MONACO, Gustavo Ferraz de Campos. Concorrência sucessória e conflito de leis. Revista Brasileira de Direito de Família, Porto Alegre, v. 7, n. 29, p. 173-184, 2005. 
MONACO, Gustavo Ferraz de Campos. Controle de constitucionalidade da lei estrangeira. São Paulo: Quartier Latin, 2013.

. Guarda internacional de crianças. São Paulo: Quartier Latin, 2012.

. La place de la constitution brésilienne et des conventions liant le Brésil dans le système de contrôle du droit étranger. In: CERQUEIRA, Gustavo Vieira da Costa; NORD, Nicolas. Contrôle de constitutionnalité et de conventionnalité du droit étranger: études de droit international privé (Amérique Latine - États-Unis - Europe). Paris: Société de Législation Comparée, 2017. v. 34, p. 173-186. (Collection Colloques).

. Problema hermenêutico da lei mais favorável em direito internacional privado à luz do desafio kelseniano. Revista IMES de Direito, São Caetano do Sul, v. 4, n. 8, p. 50-57, 2004.

NYGH, Peter Edward. The reasonable expectations of the parties as a guide to the choice of law in contract and in tort. Recueil des Cours, Leiden, v. 251, p. 269-400, 1995.

PICONE, Paolo. Les méthodes de coordination entre ordres juridique en droit international privé: cours général de droit international privé. Recueil des Cours. Leiden, v. 276, p. 9-296, 1999.

POCAR, Fausto. Il nuovo diritto internazionale privato italiano. 2. ed. Milano: Giuffrè, 2002.

RAMOS, Rui Manuel Gens de Moura. Droit international privé vers la fin du vingtième siècle: avancement ou recul? Separata de Boletim de Documentação e Direito Comparado, Lisboa, n. 73/74, p. 85-125, 1998a.

. L'ordre public international en droit portugais. Boletim da Faculdade de Direito, Coimbra, v. 74, p. $45-62,1998$ b.

RICEUR, Paul. Leituras 1: em torno ao político = Lectures 1: autour du politique. Trad. Marcelo Perine. São Paulo: Loyola, 1995.

RODAS, João Grandino. Direito internacional privado brasileiro. São Paulo: Revista dos Tribunais, 1993.

TIBURCIO, Carmen. Extensão e limites da jurisdição brasileira: competência internacional e imunidade de jurisdição. Salvador: JusPodivm, 2016.

. Temas de direito internacional. Rio de Janeiro: Renovar, 2006.

VALLADÃO, Haroldo. Direito internacional privado: em base histórica e comparativa, positiva e doutrinária, especialmente dos estados americanos. 2. ed. rev. e atual. Rio de Janeiro: Freitas Bastos, 1970 .

VICENTE, Dário Moura. Da responsabilidade pré-contratual em direito internacional privado. Coimbra: Almedina, 2001.

Impugnação da sentença arbitral e ordem pública. In: FREITAS, José Lebre de et al. Estudos em homenagem a Miguel Galvão Teles. Coimbra: Almedina, 2012. v. 2, p. 327-338. 
